\title{
Metafiz yerleşimli metastazlar
}

\author{
Metaphyseal metastases
}

\author{
Burçin Keçeci ${ }^{1}$, Murat $\mathrm{HIz}^{2}$ \\ ${ }^{1}$ Ortopedi ve Travmatoloji Uzmanı, İzmir \\ ${ }^{2}$ Cerrahpaşa Üniversitesi, Cerrahpaşa Tıp Fakültesi, Ortopedi ve Travmatoloji Anabilim Dalı, İstanbul
}

\begin{abstract}
Insan iskeleti, osteoblastlar ve osteoklastlar sayesinde yapım ve yıkım dengesi çok iyi sağlanmış bir yapıdır. Bu denge kemiğe metastaz yapan tümörler nedeniyle bozulabilir. Kemik metastazının iki ana tipi vardır: 1) Osteolitik olarak adlandırılan, kemiğin yapısını hasarlandıran tip; 2) Osteoblastik olarak adlandırılan, yeni kemik oluşumuyla karakterize tip. Bütün bu metastaz tipleri, kemiğin ana yapısını bozan özellikler taşır. Kemiğin metafiz olarak adlandırdığımız kısmı epifizin bitişiğinde, ancak büyüme plağının altında ve trabeküler kemikten oluşur. Metafiz, kılcal ağlara kıyasla kan damarlarında yavaş kan akışına neden olan sinüzoidal damar yapısına sahiptir. Vasküler sinüzoidlerdeki bu yavaş kan akışı, hematopoetik ve lenfoid hücrelerin kemik içinde ve dışında hareket etmesi için idealdir, bu durum kemiğe metastaz yapan kanser hücreleri tarafından da kullanılır. Bu bölümde kemiğin metafizer bölgesine kanser hücrelerinin metastaz yapma özellikleri ve mekanizmasından bahsedilmektedir.
\end{abstract}

Anahtar sözcükler: kemik; metastaz; karsinom; metafiz
The balance of the human skeleton is very well balanced thanks to the osteoblast and osteoclast found in the bone. This balance may be disrupted by tumors metastasizing to the bone. There are two main types of bone metastases: 1) Osteolytic, which damages the structure of the bone; 2) Osteoblastic type, characterized by the formation of new bone. All these types of metastases have features that disrupt the main structure of the bone. The metaphyseal part of the bone is adjacent to the epiphysis but under the growth plate, and consists of trabecular bone. Metaphysis has a sinusoidal vasculature that causes slow blood flow in blood vessels compared to capillary networks. This slow blood flow in vascular sinusoids is ideal for hematopoietic and lymphoid cells to move in and out of the bone, which is also used by cancer cells that metastasize to bone. In this section, the features and mechanism of metastasis of cancer cells to the metaphyseal region of the bone are discussed.

Key words: bone; metastasis; carcinoma; metaphysis
K emik; yapısal destek, kandaki kalsiyum seviyelerinin düzenlenmesi ve iç organlarının korunmasını sağlayabilen benzersiz bir organdır. ${ }^{[1]}$ Kemik dokusu, bu işlevleri yerine getirebilmek için dinamik bir yeniden modelleme sürecinden geçer. Kemik rezorpsiyonu (emilimi) ve yapımı, net kemik kazanCı veya kaybı olmadan osteoblastlar ve osteoklastlar arasında sıkı düzenlenmiş bir dengede kontrol edilir. Bununla birlikte, hastalık koşulları altında, kemik rezorpsiyonu ve yapımı arasındaki denge bozulur.

Vücutta iki tür kemik bulunur: kortikal kemik ve trabeküler kemik. Kortikal kemik, koruyucu fonksiyonlar sağlamanın yanı sıra vücudun ağırlık yükünü desteklemede hayati bir rol oynayan yoğun bir dış doku tabakasıdır. Kompakt kemik de denilen kortikal kemik, yoğun şekilde paketlenmiş kollajen fibrillerinden, özellikle de Tip I kollajenden oluşur. ${ }^{[1]}$ Kemiğin iç kısmında ve yakın kemik uçlarında yer alan trabeküler kemik, aynı zamanda süngerimsi kemik olarak da adlandırılır. Bu tip kemik, kortikal kemikten daha az yoğundur ve gözenekli bir matriksten oluşur. Kortikal kemik, vücudu desteklemek için gerekli olan iskelete kuvvet ve yapı kazandırır; trabeküler kemik ise mekanik kuvvete dayanmak için gerekli esnekliği sağlar. ${ }^{[2]}$ Humerus ve femur gibi uzun kemiklerin yanı sıra, vertebra ve sternum gibi düz ve düzensiz kemikler de ağırlıklı olarak

- İletişim adresi: Doç. Dr. Burçin Keçeci, Serbest Ortopedi ve Travmatoloji Uzmanı (Ege Üniversitesi’nden emekli), İzmir Tel: 0532 - 4401952 e-posta: kececiburcin@hotmail.com

- Geliş tarihi: 4 Ekim 2019 Kabul tarihi: 6 Kasım 2019 
trabeküler kemikten oluşur. ${ }^{[3]}$ Hem kortikal hem de trabeküler kemik metabolik olarak aktif olsa da, trabeküler kemik kortikal kemikten daha yüksek bir oranda onarımdan geçer. ${ }^{[1]}$

Uzun kemikler üç bölgeden oluşur: epifiz, metafiz ve diyafiz. Epifiz uzun kemiklerin ucunda, kemik büyümesinin ve uzamanın gerçekleştiği büyüme plağının üzerinde bulunur. Diyafiz, kemik iliği dolu bir boşluğu çevreleyen kortikal kemikten oluşan uzun kemiklerin şaftıdır (gövde kısmıdır). ${ }^{[4]}$ Metafiz, epifizin bitişiğinde, ancak büyüme plağının altında ve trabeküler kemikten oluşur. Metafiz, kılcal ağlara kıyasla kan damarlarında yavaş kan akışına neden olan sinüzoidal damar yapısına sahiptir. Vasküler sinüzoidlerdeki bu yavaş kan akışı, hematopoetik ve lenfoid hücrelerin kemik içinde ve dışında hareket etmesi için idealdir, ancak aynı zamanda kemiğe kaçak yapan kanser hücreleri de bundan yararlanır (Şekil 1). ${ }^{[5,6]}$

Uzun kemiklerin metafizer bölgeleri trabeküler kemik içerir. Yukarıda da bahsedildiği gibi, bu bölgedeki sinüzoidal damar yapısı kanser hücrelerinin de yerleşmesini kolaylaştırıcı bir etkendir. Kemik dokusu; kanser hücrelerinin yerleşmesini sağlayabilecek zengin bir büyüme faktörü, neovaskülarizasyon faktörü, sitokin ve kemokin kaynağıdır. Bu bölgeye en sık metastaz yapan kanser türleri, sırasıyla; prostat kanseri, meme kanseri ve multipl miyelomdur. ${ }^{[7-10]}$ Diğer kanser türleri de sırasıyla; akciğer ${ }^{[11,12]}$ karaciğer $^{[13]}$ böbrek ${ }^{[14]}$ ve tiroid kanseri[ ${ }^{[15]}$ olmak üzere, yukarıda saydığımız kanserlerden daha az sıklıkla kemiğe metastaz yapar.

Uzun kemiklerin metafizer bölgesine kanser metastazı olması, o bölgedeki kemik yapısını bozar. Biyomekanik olarak dayanıklılığı azalan bu doku, hastada ağrıya ve hatta patolojik kırığa bağlı fonksiyon bozukluğuna neden olur. Bu durum, hasta konforunu olumsuz yönde etkiler. Kanserlerin kemik dokusuna metastaz yapması, aynı zamanda bu hastalığın sistemik hale geçtiğini ve hastanın sağkalım süresinin de azaldığını gösteren bir bulgudur. Bu durumda, hastanın geri kalan ömrünü konforlu geçirmesini sağlamak amacıyla mutlaka metastatik kemik bölgesine tedavi uygulamak gereklidir. Kemik metastazları için uygulanacak tedavi yöntemleri kemoterapi, radyoterapi ve cerrahidir. Uygulanacak tedaviye karar vermek için en sık kullanılan sistem, Mirels'in skorlama sistemidir. ${ }^{[16]}$

Uzun kemiklerin metafizer bölgeleri, kemiklerin diğer bölgelerinden farklı bir şekilde ele alınmalıdır. Bu bölgeler büyük eklemlere komşu trabeküler kemik yapısını içerir ve burada oluşacak kemik hasarı direkt olarak eklem fonksiyonlarını da ilgilendiren bir soruna neden olur. Mirels'in skorlama sistemine göre dokuz ve üstü puan alan, yani kırık riski \%33-100 olan hastalara,

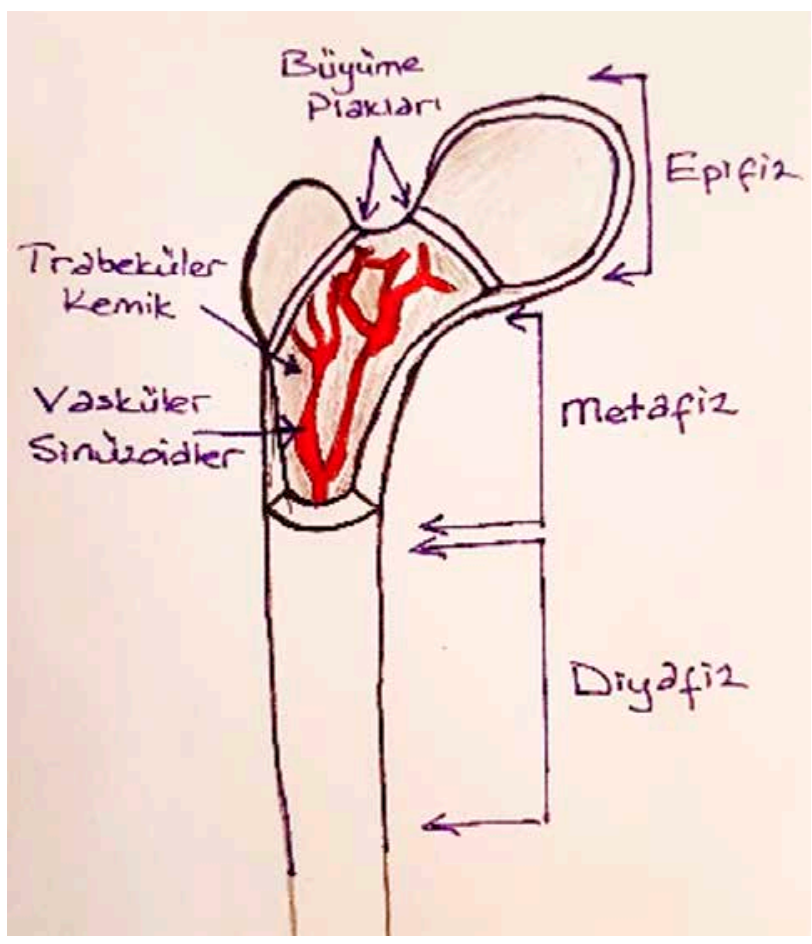

Şekil 1. Uzun kemiğin bölümleri ve yapısal özellikleri.

kırık oluşmadan önce koruyucu ve fonksiyonel cerrahi tedavi yapmak gereklidir (Şekil 2). Yapılacak cerrahiyi seçerken, hastanın ortalama yaşam süresi ve hastanın fonksiyonel kapasitesi göz önüne alınmalıdır. Uygulanacak internal tespit yöntemlerinin ya da protez uygulamalarının dayanım süresi, hastanın yaşam süresinden daha uzun olmalıdır. Humerus proksimal metafizer bölge tutulumlarında omuz eklemi fonksiyonları önemli oranda bozulacak, bu nedenle rotator cuff (rotator manşet) kaslarını ve bisepsin uzun başını koruyarak yapılacak bir endoprotez uygulaması hastanın fonksiyonel bir ekleme sahip olmasını sağlayacaktır (Şekil 3). Özellikle femur proksimalinde oluşmuş patolojik kırıkların tedavisinde konservatif yöntemler çok nadiren endikedir. Hastanın mobilizasyonunun sağlanması, ancak rijit tespit ve prostetik uygulamalarla sağlanabilir. Femur boynunun patolojik kırıkları ve bu bölgede yerleşen metastatik lezyonlar ise endoprostetik replasman ile tedavi edilmelidir. Femur boyun bölgesindeki non-deplase kırıkların bile (+/- internal tespit) kaynama şansı çok düşüktür. Femur boynuna kemik çimentosunun etkili bir şekilde uygulanamaması, rijit internal tespit elde edilmesini engeller. Femur distal metafizer tutulumlarda, eğer ekleme yakın bir tutulum varsa, oluşacak bir patolojik kırık eklem fonksiyonlarını 


\section{Metafiz lokalizyonlu Evre II - III tedavi algoritması}

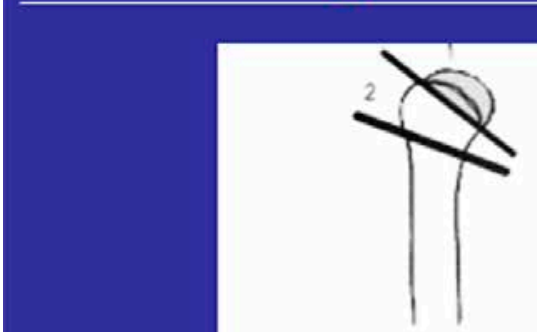

Alan 1 : Uzun stem sementli endoprotez

Alan 2 veya 1+2: B1 (Sementli megaprotez)
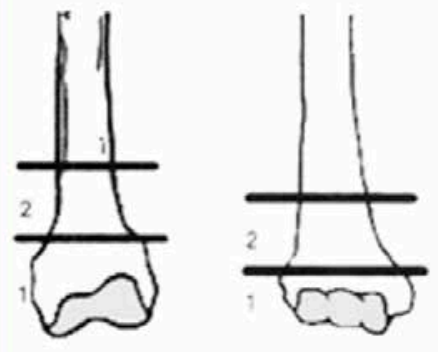

Şekil 2. Uzun kemik metafizer yerleşimli Evre II-III metastazlarında tedavi algoritması. (Prof. Dr. Nevzat Dabak'ın izniyle kullanılmıştır.)
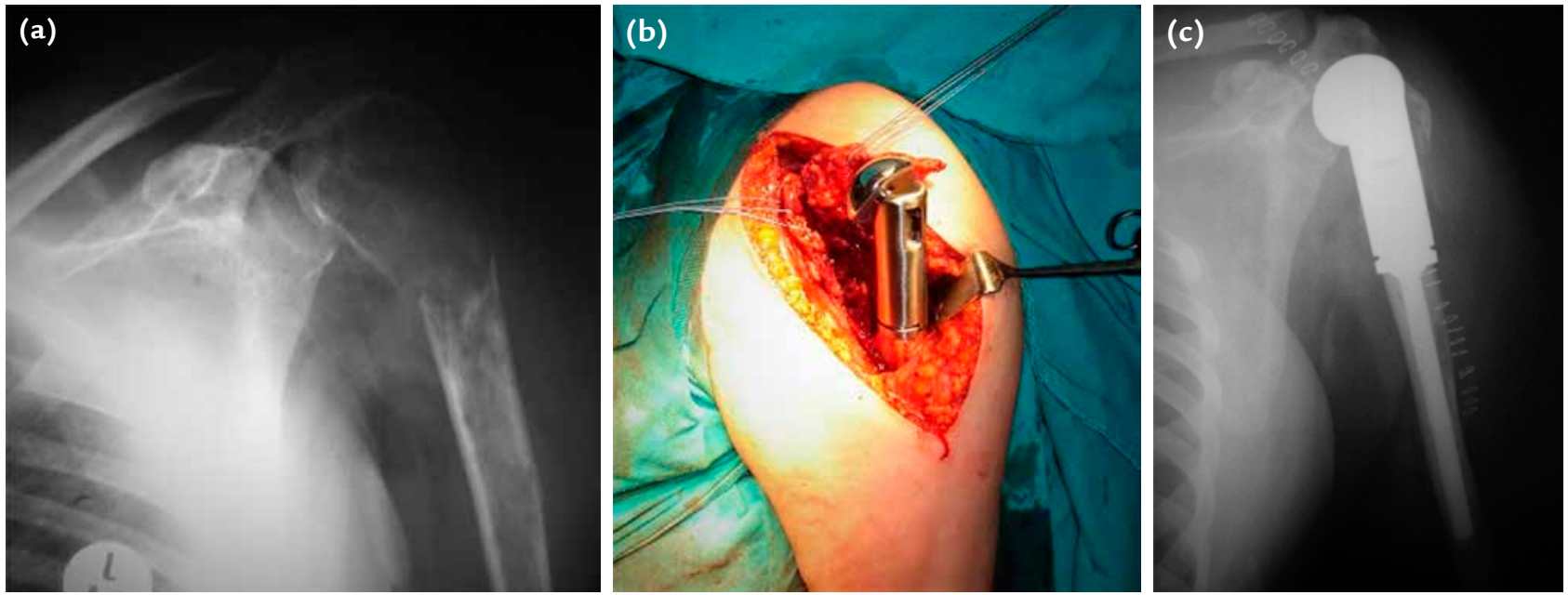

Şekil 3. a-c. Meme kanseri metastazı nedeniyle, sol humerus proksimal metafizer bölgede patolojik kırık gelişmiş 52 yaşındaki hastaya megaprotez ile rekonstrüksiyon uygulandı.

bozacağı için endoprotez uygulamaları mantıklı bir seçimdir. Metafizodiyafizer bölgede yerleşen tümörlerde, eğer çimento ve intramedüller çivileme ile rijit tespit elde edilebiliyorsa, hastanın kendi eklemi korunarak çok daha fonksiyonel bir sonuç elde edilebilir (Şekil 4). Genel durumu anestezi alamayacak kadar bozuk olan hastalarda kırık oluşmasını engellemek, patolojik kırık oluşmuş ise rahat mobilize edebilmek için ortez ve vücut dışı protezler kullanılmalıdır (Şekil 5). Bütün bu uygulanan tedavilerin tek bir ortak amacı vardır: hastanın kalan ömrünü konforlu ve ağrısız bir şekilde geçirmesini sağlayabilmek. 


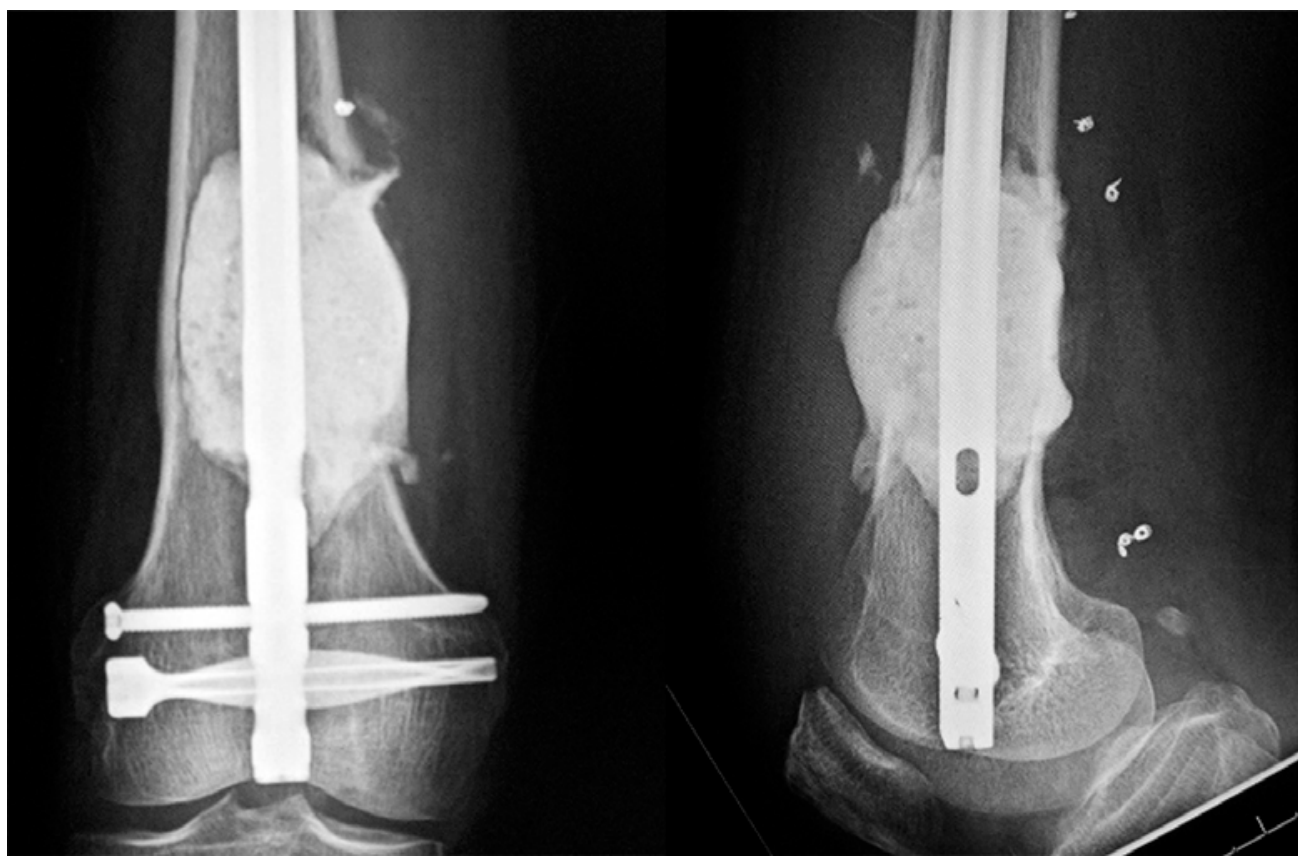

Şekil 4. Akciğer kanseri metastazı nedeniyle kemik çimentosu ve intramedüller kilitli çivi uygulaması.

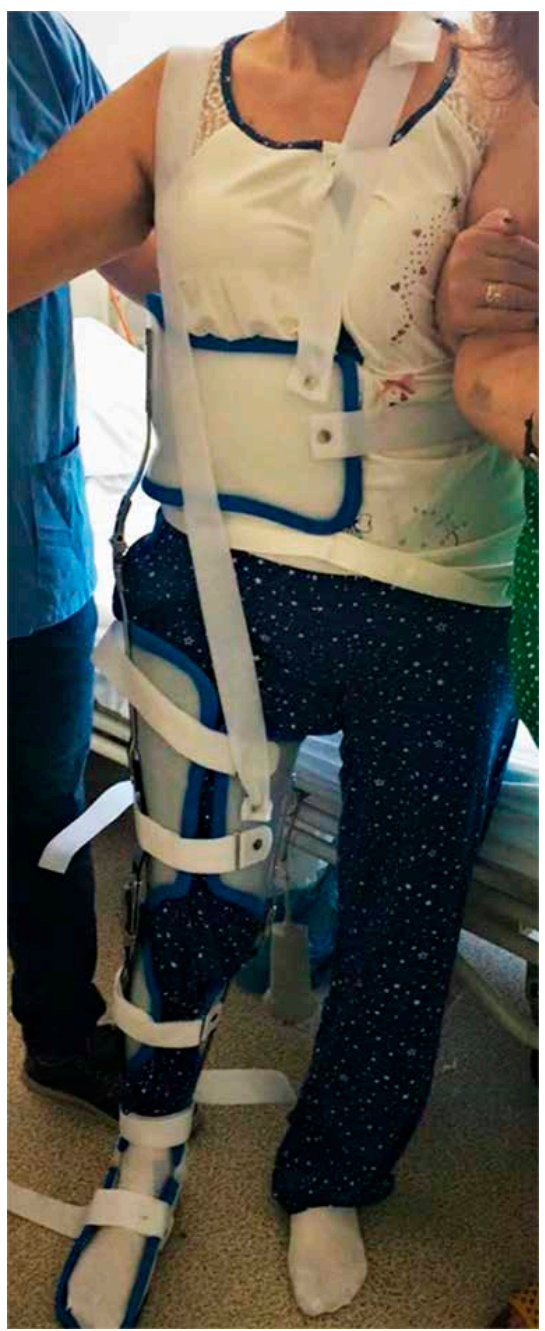

Şekil 5. Sol proksimal femur bölgesinde kırık riski olan ve radyoterapi alan hastamıza uygulanan bel destekli uzun bacak yürüme ortezi.

\section{KAYNAKLAR}

1. Marks SC Jr, Odgren PR. Structure and development of the skeleton. In: Bilezikian JP, Raisz LG, Rodan GA, editors. Principles of Bone Biology, 2nd ed., Volume 1. San Diego, CA, USA. Academic Press; 2002. pp. 3-16.

2. Oftadeh R, Perez-Viloria M, Villa-Camacho JC, Vaziri A, Nazarian A. Biomechanics and mechanobiology of trabecular bone: A review. J Biomech Eng 2015;137(1):010802. Crossref

3. Keaveny TM, Morgan EF, Niebur GL, Yeh OC. Biomechanics of trabecular bone. Annu Rev Biomed Eng 2001;3(1):30733. Crossref

4. Price JS, Oyajobi BO, Russell RG. The cell biology of bone growth. Eur J Clin Nutr 1994;48(Suppl 1);S131-49.

5. Bussard KM, Gay CV, Mastro AM. The bone microenvironment in metastasis; what is special about bone? Cancer Metastasis Rev 2008;27(1):41-55. Crossref

6. Mazo IB, von Andrian UH. Adhesion and homing of bloodborne cells in bone marrow microvessels. J Leukoc Biol 1999;66(1):25-32. Crossref

7. Wang N. Docherty FE, Brown HK, Reeves KJ, Fowles AC, Ottewell PD, Dear TN, Holen I, Croucher PI, Eaton CL. Prostate cancer cells preferentially home to osteoblast-rich areas in the early stages of bone metastasis: Evidence from in vivo models. J Bone Miner Res 2014;29(!2):2688-96. Crossref

8. Belic J, Graf R, Bauernhofer T, Cherkas Y, Ulz P, WaldispuehlGeigl J, Perakis S, Gormley M, Patel J, Li W, Geigl JB, Smirnov D, Heitzer E, Gross M, Speicher MR. Genomic alterations in plasma DNA from patients with metastasized prostate cancer receiving abiraterone or enzalutamide. Int J Cancer 2018;143(5):1236-48. Crossref

9. Pulido C, Vendrell I, Ferreira AR, Casimiro S, Mansinho A, Alho I, Costa L. Bone metastasis risk factors in breast cancer. Ecancermedicalscience 2017;11:715. Crossref 
10. Greenberg AJ, Rajkumar SV, Therneau TM, Singh PP, Dispenzieri A, Kumar SK. Relationship between initial clinical presentation and the molecular cytogenetic classification of myeloma. Leukemia 2014;28(2):398-403. Crossref

11. Santini $D$, Barni $S$, Intagliata $S$, Falcone $A$, Ferraù $F$, Galetta $D$, Moscetti L, La Verde N, Ibrahim T, Petrelli F, Vasile E, Ginocchi L, Ottaviani D, Longo F, Ortega C, Russo A, Badalamenti G, Collovà E, Lanzetta G, Mansueto G, Adamo V, Marinis FD, Satolli MA, Cantile F, Mancuso A, Tanca FM, Addeo R, Russano M, Sterpi M, Pantano F, Vincenzi B, Tonini G. Corrigendum: Natural history of non-small-cell lung cancer with bone metastases. Sci Rep 2016;6(1):22205. Crossref

12. Santini $D$, Barni $S$, Intagliata $S$, Falcone $A$, Ferraù $F$, Galetta D, Moscetti L, La Verde N, Ibrahim T, Petrelli F, Vasile E, Ginocchi L, Ottaviani D, Longo F, Ortega C, Russo A, Badalamenti G, Collovà E, Lanzetta G, Mansueto G, Adamo V, De Marinis F, Satolli MA, Cantile F, Mancuso A, Tanca FM, Addeo R, Russano M, Sterpi M, Pantano F, Vincenzi B, Tonini G. Natural history of non-small-cell lung cancer with bone metastases. Sci Rep 2015;5:18670. Crossref
13. Kim S, Chun M, Wang $\mathrm{H}$, Cho $\mathrm{S}$, Oh $\mathrm{Y}-\mathrm{T}$, Kang $\mathrm{S}-\mathrm{H}$, Yang $\mathrm{J}$. Bone metastasis from primary hepatocellular carcinoma: Characteristics of soft tissue formation. Cancer Res Treat 2007;39(3):104-8. Crossref

14. Chen S-C, Kuo P-L. Bone metastasis from renal cell carcinoma. Int J Mol Sci 2016;17(6):987. Crossref

15. Durante C, Haddy N, Baudin E, Leboulleux S, Hartl D, Travagli JP, Caillou B, Ricard M, Lumbroso JD, De Vathaire F, Schlumberger M. Long-term outcome of 444 patients with distant metastases from papillary and follicular thyroid carcinoma: Benefits and limits of radioiodine therapy. J Clin Endocrinol Metab 2006;91(8):2892-9. Crossref

16. Mirels $\mathrm{H}$. Metastatic disease in long bones: a proposed scoring system for diagnosing impending pathologic fractures. Clin Orthop Relat Res 1989;(249):256-64. Crossref 